\title{
Extração e Comercialização de Folhagens Ornamentais da Mata Atlântica: o Caso da Verdes (Rumohra adiantiformis) no RS
}

\author{
Rafael Perez Ribas ${ }^{* *}$ \\ Lovois de Andrade Miguel ${ }^{* * *}$
}

Resumo: Este trabalho restitui os resultados de uma pesquisa sobre a comercialização de samambaia-preta (Rumohra adiantiformis (G. Forst) Ching), também conhecida como verdes, que é extraída na região da Encosta Atlântica do Rio Grande do Sul. Além de ser considerada uma das maiores regiões produtoras desta folhagem no Brasil, um número significativo de agricultores familiares desta região tem na extração desta espécie sua principal fonte de renda. Os resultados deste estudo permitem perceber a existência de uma remuneração bastante diferenciada entre os diferentes agentes envolvidos, salientando o predomínio de relações de cunho comercial precárias e informais, e a inexistência de representação e organização dos atores envolvidos. Tal situação pode ser imputada, em grande parte, ao caráter ilegal e clandestino desta atividade, tendo em vista a legislação ambiental vigente no Estado do Rio Grande do Sul.

\footnotetext{
* Trabalho apresentado no VIII Encontro Nacional de Economia Política e no XLI Congresso de Economia e Sociologia Rural, em 2003.

** Economista pela Universidade Federal do Rio Grande do Sul (UFRGS), mestrando em Economia na Universidade Federal de Minas Gerais (CEDEPLAR-UFMG). e-mail: rpribas@cedeplar.ufmg.br

${ }^{* * *}$ Doutor em Agricultura Comparada e Desenvolvimento Agrícola pelo Institut National Agronomique Paris Grignon (INA-PG), França, e Professor Adjunto do Departamento de Ciências Econômicas e do Programa de Pós-Graduação em Desenvolvimento Rural (PGDR) da Universidade Federal do Rio Grande do Sul (UFRGS).
} 
Palavras-chave: Samambaia-preta; Extrativismo; Comercialização; Mata Atlântica.

\section{Classificação JEL: L70; Q21; Q58}

Abstract: This work shows the results of research on the leather fern (Rumohra adiantiformis (G. Forst.) Ching) trade that it's extracted at the Atlantic Slope region of Rio Grande do Sul. Besides being considered one of the greatest fern producing regions of Brazil, a significant number of local family farmers have in the extraction of this species their main income source. The results of this study allowed us to verify the existence of a very differentiated compensation in different agents involved, emphasizing the predominance of precarious and informal commercial relations, and the inexistence of representation and organization of the involved players. This situation is a consequence of the illegal and clandestine character of this activity, in view of the effective environmental legislation in Rio Grande do Sul State.

Keywords: Leather Fern; Extraction; Trading; Atlantic Forest.

JEL Classification: L70; Q21; Q58.

\section{Introdução}

A extração de folhagens na região da Encosta Atlântica do Estado do Rio Grande do Sul é uma atividade, tanto no que tange aos aspectos econômicos como sociais e ambientais, de relevante importância para a economia dos municípios de Maquiné, Osório e Caraá, ponto de partida deste estudo.

A espécie Rumohra adiantiformis (G. Forst.) Ching (DryopteridaceaePteridophyta), conhecida popularmente como samambaia-preta ou verde ${ }^{1}$, possui uma distribuição geográfica bastante ampla, sendo conhecida em ambos os trópicos e nas regiões temperadas do sul (MILTON \& MOLL, 1988). No Rio Grande do Sul ocorre nos mais diversos ambientes, sendo

${ }^{1}$ Conhecida no comércio internacional como leather fern, leatherleaf fern, pereg, ou hoja de cuero. 
particularmente abundante nos domínios da Floresta Atlântica. Esta planta exibe grande plasticidade ecológica, podendo ocorrer em diversos habitats (restingas, rochedos, capoeiras e florestas) e com diferentes formas biológicas (terrestres, rupestres e epifíticas) (ANAMA, PGDR-UFRGS, RS-RURAL, 2003). Destaca-se dentre as demais pteridófitas por sua importância econômica, sendo suas folhas comercializadas em nível mundial para utilização em arranjos de flores. As folhas comercializadas são obtidas, na maioria das vezes, através da extração direta em seu ambiente natural.

Na Encosta Atlântica do Rio Grande do Sul (região compreendida pelo Litoral Norte), a coleta da samambaia-preta teve início na década de 1970 e intensificou-se nas décadas seguintes, envolvendo um número crescente de famílias inviabilizadas de cultivarem suas áreas agrícolas, seja pelas restrições da legislação ambiental $^{2}$ ou pela disponibilidade restrita de áreas apropriadas ao cultivo (GERHARDT \& MIGUEL, 2001). Atualmente, estimase que 3 mil agricultores familiares da região têm na extração da samambaia-preta a sua principal fonte de renda (GERHARDT et. al., 2000).

Se por um lado, a extração da samambaia é uma fonte de renda fundamental para um número significativo de agricultores familiares locais, por outro lado, muito pouco se conhece sobre a cadeia de comercialização desta espécie em sua totalidade.

A complexa problemática vivenciada pelos agricultores familiares extrativistas da região engendrou, nos últimos anos, alguns estudos e pesquisas tanto de cunho acadêmico como de cunho técnico por parte dos poderes públicos, universidades e organizações não-governamentais. Entre os estudos e pesquisas atualmente em realização, cabe salientar o projeto multidisciplinar intitulado "Avaliação etnobiológica e socioeconômica da samambaia-preta (Rumohra adiantiformis (G.Forest.) Ching) na região da Encosta Atlântica do Estado" (COELHO DE SOUZA et. al., 2000)³.

\footnotetext{
${ }^{2}$ Decreto 750 de 10/02/1993

${ }^{3}$ O projeto teve início em 2000, financiado pelo componente Pesquisa por Demanda do Programa RS-Rural da Secretaria da Agricultura e Abastecimento do RS. Entre seus objetivos, ele busca elaborar fundamentos técnicos-científicos que subsidiem o licenciamento desta atividade extrativista, avaliando os impactos ambientais, sociais e econômicos do extrativismo sobre as populações "samambaieiras" da região de estudo, compreendida entre os municípios de Maquiné, Caraá e Osório, “pólos” extrativistas dentro da Encosta Atlântica do RS. Espera-se assim auxiliar na elaboração de propostas de ações e políticas em prol do desenvolvimento sustentável desta região.
} 
Inserido na avaliação socioeconômica desse projeto, o estudo de comercialização em questão tem como objetivo específico analisar os atores e grupos que intervêm na cadeia e suas inserções nos diferentes mercados e setores, buscando compreender as principais rotas comerciais e apontando as características econômicas do produto e dos agentes envolvidos.

O presente artigo está estruturado em quatro partes distintas: descrição das características e dos problemas deste extrativismo no Rio Grande do Sul; delineamento do método utilizado para coleta e análise das informações; apresentação dos resultados obtidos; e, por fim, uma reflexão sobre a contribuição desta pesquisa com vistas à organização das relações comerciais em torno da samambaia-preta.

\section{Características e Problemas do Extrativismo}

No Estado do Rio Grande do Sul, onde os remanescentes florestais da Mata Atlântica cobrem cerca de 5,9\% da área total, a área tombada pela Reserva da Biosfera da Mata Atlântica (RBMA) e seus ecossistemas associados abrange uma superfície de $29.319 \mathrm{~km}^{2}$, totalizando $10 \%$ do território do Estado. A Bacia Hidrográfica do Rio Maquiné, na Encosta Atlântica do Litoral Norte gaúcho, foi uma das regiões selecionadas como áreas piloto da RBMA.

De uma maneira geral, essa região tem sido submetida a um intenso processo de extração da samambaia-preta. Trata-se de uma atividade, que envolve uma parcela considerável da população local, seja através da coleta, do arrendamento de terras, ou do transporte e venda a grandes centros consumidores no País.

No entanto, a população envolvida em atividades extrativistas é fortemente marcada por uma vulnerabilidade perante a legislação ambiental estadual atualmente em vigor. Segundo a legislação, encontra-se proibido o comércio das espécies nativas da Floresta Atlântica ${ }^{4}$ (FEPAM, 2000). Esta situação faz da extração da samambaia-preta uma atividade instável e precária, mantendo-a em situação de clandestinidade.

${ }^{4}$ Art. 38 da Lei Estadual n. ${ }^{0} 9.519$ de 21/01/1992, que institui o Código Florestal do RS. 
Na África do Sul, na região do Cabo, proprietários de terra suprem o mercado local, desde a década de 1970, através da extração da samambaia do ambiente natural. Após a permissão do Departamento de Florestas daquela região para exploração comercial em 4 mil hectares de florestas do Estado, essa atividade econômica desenvolveu-se rapidamente, tornando-se o principal produto dessa região, caracterizada por uma economia decadente (MILTON \& MOLL, 1988). Nos Estados Unidos, não ocorrem populações naturais, sendo essa espécie cultivada comercialmente em viveiros irrigados. A maioria das folhas vendidas no mercado europeu é produzida no Estado da Flórida (EUA) (MILTON \& MOLL, 1988). No Brasil, grande parte do mercado nacional é abastecida pelas folhas extraídas no Rio Grande do Sul, sendo todas elas obtidas através da extração direta em seu ambiente natural.

O Decreto 38.355 de 01/04/98 estabelece as normas básicas para o manejo dos recursos florestais nativos e prevê o licenciamento para a coleta de produtos ou subprodutos florestais não madeiráveis. No caso da extração da samambaia-preta, a sua coleta é passível de licenciamento, desde que sejam conhecidos alguns fundamentos técnicos que incluem, entre outros itens, o estudo sobre a produtividade da espécie explorada, sua demografia e interações com outras plantas, o impacto ambiental causado pela atividade extrativista e os procedimentos e alternativas que minimizem esse impacto, além do estudo de impactos sócio-econômicos (ANAMA, PGDR-UFRGS, RS-RURAL, 2003 e FEPAM, 2000).

Ao proporcionar medidas que assegurem a preservação ambiental, a legislação impede que extrativistas, representados em grande parte por pequenos agricultores familiares, possam produzir e assegurar a sua reprodução social no meio rural desta região. Esta situação tem acelerado o processo de empobrecimento destes pequenos agricultores, acarretando a intensificação da migração campo-cidade e determinando o esvaziamento do meio rural desta região (GERHARDT et. al., 2000). A situação de clandestinidade e importância social desta atividade de extração tem suscitado inclusive, nos últimos anos, reações por parte da imprensa local e estadual 5 .

5 “A extração e o comércio de samambaias, bem como de qualquer outra espécie da Mata Atlântica, são proibidos por leis federais e estaduais. Mesmo assim, da colheita nos 
Contrário ao que é veiculado pelo senso comum (imprensa e poderes públicos), que coloca a atividade extrativista confrontada com uma progressiva redução dos estoques naturais, este processo de redução, no caso da samambaia-preta, também é um processo natural e está relacionado com a redução do desmatamento na região. Alguns estudos etnobotânicos realizados apontam que a Rumohra adiantiformis é uma “pioneira”, desenvolvendo-se com maior densidade em locais cobertos por uma vegetação arbustiva não muito densa. Em decorrência disto, constata-se que o processo de regeneração da Mata Atlântica contribui para uma progressiva diminuição deste recurso (ANAMA, PGDR-UFRGS, RS-RURAL, 2003).

Dessa forma, o problema local volta-se ao conflito entre preservação ambiental e reprodução social via esta atividade extrativista e, principalmente, às condições de mercado para o produto, foco desse trabalho. Importante é salientar que, devido à clandestinidade das atividades desenvolvidas, são quase inexistentes as políticas públicas voltadas a essas famílias, enquadradas numa situação de pobreza rural.

\section{Metodologia}

O estudo da cadeia de comercialização está fundamentado no conceito de analyse de filière. Desenvolvido pela Escola Industrial Francesa, ao longo da década de 1960 do século passado, este conceito, apesar de seguir uma lógica de encadeamento de atividades semelhantes à usada por Ray Goldberg (1968, apud BATALHA, 1997) na commodity system approach, difere, segundo o objeto de estudo pretendido, no ponto de partida da análise. Este método ressalta a importância, segundo Louis Malassis (1973, apud GRAZIANO DA SILVA, 1996), do fenômeno de "concorrência heterogênea” entre agentes com poder de mercado distintos.

Filière, traduzido para o português pela expressão "cadeia produti-

morros até a revenda à beira da BR-101, tudo é feito às claras, sem qualquer repressão. Moradores da região sobem os morros para colher os ramos, que são cortados em pequenos caminhões ou camionetes e levados até depósitos situados ao longo da BR-101" (ZERO HORA, 2000, p. 50). Esta mesma reportagem coloca a extração da samambaia como o mais escancarado dos saques que ocorrem diariamente contra o último vestígio de Mata Atlântica do RS com a conivência das autoridades gaúchas. 
va”, é apontado por Zylbersztajn (2000) como o aparelho que concerne a ligação entre os agentes e as operações que contribuem à formação e transferência do produto até seu estado final de utilização, enfocando a dependência dentro do sistema como um resultado da estrutura de mercado ou de forças externas.

Neste estudo, delimitou-se a filière da samambaia-preta no Litoral Norte do Rio Grande do Sul como sendo o objeto de estudo. E, baseado no trabalho de Sartor (2001), optou-se pela utilização do método de filière 'simplificada', justificada pela inexistência de elementos que convencionalmente compõem uma análise completa de cadeia como, por exemplo, a transformação do produto e a utilização de insumos e, principalmente, pela dificuldade em se conseguir informações a respeito dessa atividade.

A estrutura utilizada está fundamentada em três subsistemas (produção, transferência e consumo) representados por seis agentes distintos: extrativista (produtor primário), intermediário primário, intermediário secundário, intermediário terciário, atacadista, varejista. Cada agente é composto por diferentes atores, de acordo com suas características específicas, ligadas por suas relações comerciais.

A pesquisa de campo foi realizada em duas etapas distintas. A primeira foi realizada no decorrer no segundo semestre de 2001 e tinha como finalidade delimitar a região de estudo, reconstituir o histórico desta atividade, assim como identificar os principais atores envolvidos, a partir de entrevistas com lideranças locais.

A segunda fase, realizada nos meses de janeiro de 2002 a janeiro de 2003, consistiu na realização de entrevistas com agentes diretamente ligados à atividade, selecionados de forma não aleatória. Selecionandose sete extratores de samambaia, assim como os intermediários com os quais mantinham relações comerciais, para um acompanhamento semanal ao longo de um ano civil. Os critérios utilizados para a escolha dos entrevistados levaram em conta principalmente a disponibilidade dos meios de produção, a localização geográfica ${ }^{6}$, o volume de comercialização e o destino da produção ${ }^{7}$.

${ }^{6}$ Linha Pedra Branca, Fraga, Linha Padre Vieira e Varzinha, de Caraá; Solidão, Linha Rio Ligeiro, Espraiado, Morro Alto e Barra do Ouro, de Maquiné; Borússia e Goiabeira, de Osório. 
As principais questões levantadas nas entrevistas estavam relacionadas aos preços pagos e preços recebidos, origem e destino do produto, relações de troca entre os agentes e estrutura dos recursos necessários para a atividade, além das formas e relações de trabalho e dados históricos. Cabe salientar que, para salientar a inflexibilidade dos preços em alguns pontos da cadeia, utilizaram-se preços nominais ao invés de deflacionados.

Na análise das informações, elaborou-se uma série temporal para cada ator envolvido na amostra, com as médias ponderadas agregando os períodos. Utilizando-se a partir disso, análise de regressão simples e múltipla ${ }^{8}$. Além de análise da estacionalidade do volume comercializado (medido em "malas") com uso de índices sazonais pelo Método da Porcentagem das Médias Móveis (FONSECA, MARTINS, TOLEDO, 1985), para amostras com mais de um ano, e de médias aritméticas das amostras, para dados coletados somente em 2002.

Em relação à estrutura do mercado, buscou-se identificar as características dos diferentes conjuntos de firmas (ou indivíduos), na relação entre oferta e demanda, que se apresentam ao longo da cadeia, de acordo com o número de concorrentes, formação dos preços, formas de concorrência e concílios ${ }^{10}$ (VARIAN, 1992; KUPFER \& HASENCLEVER, 2002).

\section{Análise dos agentes envolvidos}

Ao analisarmos os diferentes grupos de agentes, ligados à produção, intermediação e comercialização final da samambaia-preta, ou verdes, pode-se constatar uma considerável diversidade de situações no inte-

\footnotetext{
${ }^{7}$ Selecionamos como destino da produção cinco grandes mercados atacadistas, Porto Alegre, Curitiba, Campinas, São Paulo e Holambra; e três tipos de comércio varejista (floriculturas), todos em Porto Alegre.

${ }^{8}$ A análise de regressão foi feita através do método de Mínimos Quadrados Ordinários (MQO) e Mínimos Quadrados em Dois Estágios (MQ2E) na busca de correlações entre preços e volumes entre os diferentes agentes, assim como na constatação de tendências estocástica e/ou determinística. Utilizaram-se o teste $t$ de Student na hipótese de correlação entre as variáveis e o teste de Durbin-Watson de autocorrelação, ambos com $5 \%$ de significância (GUJARATI, 2000; GREENE, 1997).

${ }^{9}$ Unidade de medida correspondente a, em média, 60 frondes de samambaia-preta, com um peso variando entre 1,4 e $2,0 \mathrm{~kg}$.

${ }^{10}$ Optou-se pela não elaboração de índices de concentração em decorrência da inconsistência dos dados.
} 
rior de cada grupo. Na Figura 1, buscou-se representar as diferentes rotas comerciais do produto, seguido das características dos atores que intervêm nesta cadeia.

Figura 1: Fluxograma da cadeia produtiva da samambaia-preta

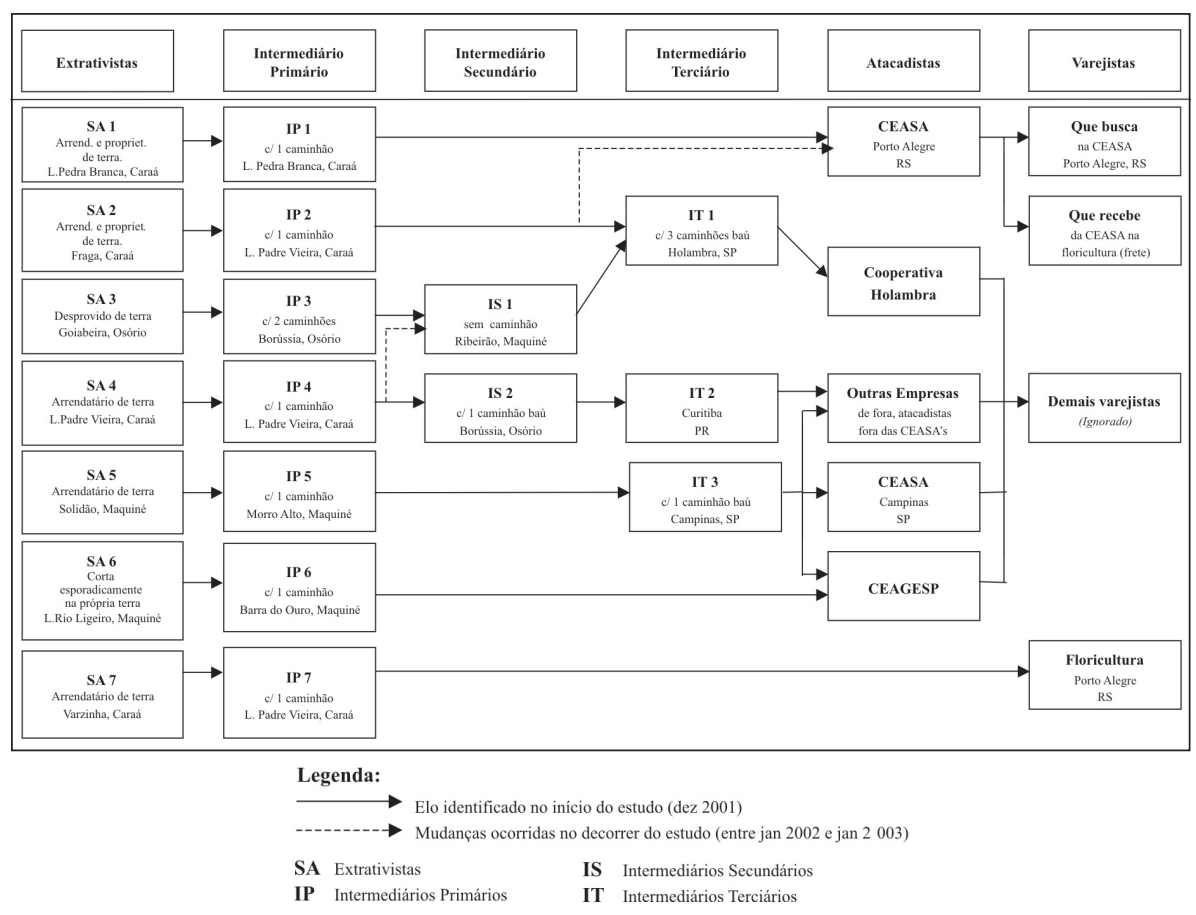

Fonte: Pesquisa de Campo, 2001/2002.

\subsection{Caracterização dos agentes envolvidos com a produção primária}

Os agentes ligados à "produção" da samambaia (ou seja, os extrativistas) apresentaram diferenças relacionadas à posse e disponibilidade de terra, à dependência do extrativismo como fonte de renda, ao grau de diversificação do sistema produtivo e às estratégias de comercialização.

Em relação à terra, foi identificado que parte dos agricultores familiares que se dedicam à extração da samambaia, não possui áreas propícias à realização da atividade ou possuem estas áreas em tamanho reduzido. Essa condição obriga estes agricultores a arrendarem áreas pertencentes 
Extração e Comercialização de Folhagens Ornamentais da Mata Atlântica: o Caso da Verdes (Rumohra adiantiformis) no RS*

aos vizinhos, em sua maioria, agricultores aposentados. As condições de arrendamento destas áreas são bastante variáveis, ocorrendo situações de cedência da exploração sem ônus, ou mesmo casos onde a cedência pode alcançar um custo de até $30 \%$ da renda bruta obtida com a venda da samambaia (RIBAS et. al., 2002).

Com relação ao sistema produtivo utilizado e à dependência econômica dos agricultores para com a atividade de extração, foram identificados aqueles que realizam a coleta com uma freqüência semanal, não desenvolvendo praticamente nenhuma atividade agrícola destinada ao autoconsumo. Igualmente identificaram-se famílias que desenvolvem algumas atividades agrícolas para autoconsumo e, em menor número, agricultores que apresentam uma diversificada produção agrícola, tanto para autoconsumo como para venda, realizando cortes esporádicos da folhagem. Sendo que a maioria da população envolvida tem nessa extração sua principal fonte de renda.

A extração da samambaia ocorre durante todo o ano, mas os meses de verão (sobretudo os meses de janeiro e fevereiro) se caracterizam por uma expressiva diminuição da atividade. Tal situação está relacionada à migração pendular de agricultores, que buscam empregos temporários no comércio das cidades litorâneas. Nos meses de inverno, devido à elevada ocorrência de chuvas e às baixas temperaturas, tendo por conseqüência um aumento da penosidade do trabalho, e primavera, devido à época de plantio das culturas de verão, alguns extratores tendem a reduzir a quantidade extraída.

Com o objetivo de garantir um fornecimento constante do produto, alguns intermediários primários estabelecem acordos informais com parte dos extratores locais. Estas relações privilegiadas garantem aos extratores a manutenção de "cotas" semanais durante todo o ano (tanto nos períodos de maior como nos períodos de menor demanda) e aos intermediários primários um fornecimento de produto estável e constante durante todos os meses.

No entanto, relações de cunho informal e de pouco comprometimento são comuns entre a maioria. Sendo que, no caso de redução de oferta de folhagens ou, excepcionalmente, aumento nos preços por parte dos extrativistas, os intermediários primários facilmente alteram seus fornecedores, devido ao elevado número de ofertantes. 
Nos preços pagos, constatou-se uma disparidade entre os extratores. Esta diferença está relacionada diretamente com o destino e a qualidade $^{11}$ do produto. Quando a samambaia extraída destina-se a outros estados, cada "mala" é vendida entre $\mathrm{R} \$ 0,35$ e $\mathrm{R} \$ 0,40$. Quando o destino é o mercado gaúcho, o extrativista recebe pela mesma "mala" R\$ 0,50 . No que tange à produção destinada ao mercado do RS, o mercado consumidor (floriculturas) exige um produto com padrão de qualidade superior. Conjuntamente com um menor número de elos de intermediação, este foco do mercado contribui para proporcionar uma melhor remuneração para os extrativistas.

\subsection{Caracterização dos agentes envolvidos com a intermediação}

Assim como na extração, a intermediação também apresenta uma elevada diversidade de agentes. As diferenças destes estão relacionadas à capacidade de acessar mercados consumidores. Neste trabalho, eles foram divididos entre intermediários primários (IPs), secundários (ISs) e terciários (ITs).

Os Intermediários Primários (IPs), conhecidos popularmente como “atravessadores”, são os menores agentes tanto pelo volume comercializado como pela infra-estrutura disponível. São moradores da região que possuem algum veículo de pequeno ou médio porte para o transporte de carga, recolhendo samambaia dos agricultores de uma a cinco vezes por semana, encaminhando a produção para os demais agentes. Eles intervêm com diferentes estratégias: venda direta do produto para as floriculturas da região metropolitana de Porto Alegre e cidades próximas ou para empresas instaladas dentro da CEASA de Porto Alegre, ou, na maioria das vezes, venda do produto para os Intermediários Secundários (ISs), também moradores da região.

\footnotetext{
${ }^{11}$ Os critérios para a avaliação de qualidade do produto são: em relação à sua cor, verde escuro sem manchas; à sua textura, folhas grandes e rígidas; pela quantidade de soros, preferencialmente sem; e pelo menor percentual de folhas danificadas em uma "mala". A qualidade pode ser diferenciada pelo local de ocorrência; as folhas coletadas em áreas mais sombreadas (capoeira alta) são maiores, mais lisas - ideal para o mercado consumidor, contudo ocorrem em menor quantidade e apresentam menor durabilidade; as coletadas em áreas de maior incidência de luz (macega ou capoeira baixa) são mais crespas, mais grossas e menores, mas ocorrem em maior quantidade e maior durabilidade (ANAMA, PGDR-UFRGS, RS-RURAL, 2003).
} 
Os ISs são quem geralmente detêm contato e relações com empresas de fora do estado e, apesar de não incorrerem elevados custos, possuem um grau de risco maior perante à atividade. São raros os IPs que negociam com outros estados, devido justamente a este grau de risco exigido.

Os Intermediários Terciários (ITs) deslocam de outros estados, na maioria São Paulo, caminhões do tipo "baú” (ou seja, com uma carroceria metálica fechada) semanalmente para buscar o produto na região do Litoral Norte do RS. Passam pelos ITs certamente a maioria do produto extraído nas encostas da Serra Geral do litoral rio-grandense. Os ITs revendem o produto para empresas instaladas nas Centrais de Abastecimento (identificados neste trabalho como atacadistas) do resto do País ou diretamente para o comércio varejista localizado nas regiões Sul e Sudeste.

A relação comercial entre intermediários locais e de fora do estado não envolve nenhum tipo de contrato escrito, limitando-se a acordos verbais. Fato que tem acarretado um elevado grau de inadimplência, pois os intermediários terciários certas vezes realizam os pagamentos com cheques de terceiros, seguidamente sem fundos. Os prejuízos são geralmente absorvidos, nestas situações, pelos IPs e, em maior parte, pelos ISs.

Os preços agregados pelos IPs também se diferenciam de acordo com o destino do produto. Entre aqueles que negociam com ISs, a margem é de $\mathrm{R} \$ 0,15$ a $\mathrm{R} \$ 0,20$, de acordo com a origem do produto. Quando a produção é vendida diretamente aos ITs, a margem aumenta para R 0,25 0,30. E quando o comércio é diretamente feito com empresas da Região Metropolitana de Porto Alegre, ocorre a maior margem, $\mathrm{R} \$ 0,40-0,50$.

Os intervalos com os preços de compra e venda, que tem como destino outros estados que não o RS, estão restituídos na Tabela 1.

Tabela 1 - Faixa de preços ( $\mathrm{R}$ \$ por mala) de compra e venda da samambaia-preta entre as diferentes fases de intermediação, do Litoral Norte do RS para outros estados:

\begin{tabular}{|c|c|c|c|c|}
\hline & $\begin{array}{c}\text { Intermediário } \\
\text { Primário }\end{array}$ & $\begin{array}{c}\text { Intermediário } \\
\text { Secundário }\end{array}$ & $\begin{array}{c}\text { Intermediário } \\
\text { Terciário }\end{array}$ & Atacadistas \\
\hline $\begin{array}{c}\text { Preço Compra } \\
\text { (R\$ por mala })\end{array}$ & $0,35-0,40$ & 0,55 & $0,60-0,70$ & $1,60-1,70$ \\
\hline $\begin{array}{c}\text { Preço Venda } \\
\text { (R\$ por } \text { mala })\end{array}$ & $0,55-0.60$ & $0,65-0,70$ & $1,25-1,70$ & $2,50-4,00$ \\
\hline
\end{tabular}

Fonte: Pesquisa de campo, 2002. 
As avaliações e análises acerca dos preços praticados nesta cadeia apontam para a existência de uma remuneração irregular e desequilibrada entre os agentes. A tabela acima permite constatar que maior parte do valor do produto é agregado fora do estado do RS, entre os ITs e comerciantes atacadistas.

Em alguns casos entre ITs, muito desse valor agregado é justificado pelos elevados custos em transporte. Para fazer frente a esta situação, muitas empresas que buscam a samambaia no Litoral Norte gaúcho são, ao mesmo tempo, transportadoras de alimentos ou flores. O transporte de folhagens é uma forma de diminuir a ociosidade no retorno dos caminhões, evitando que estes retornem vazios ao centro do país. No entanto, constataram-se outros casos que nem todo valor agregado ao preço é justificado pelos custos de transporte, identificando lucros elevados junto a alguns ITs que manipulam grandes volumes de folhagem ${ }^{12}$.

A sazonalidade do volume das vendas é reconstituída no Gráfico 1, apresentando a média amostral das semanas de saída de "malas" ao longo de um ano na região de estudo.

Gráfico 1 - Média amostral do volume de vendas dos Intermediários Primários ao longo do ano de 2002:

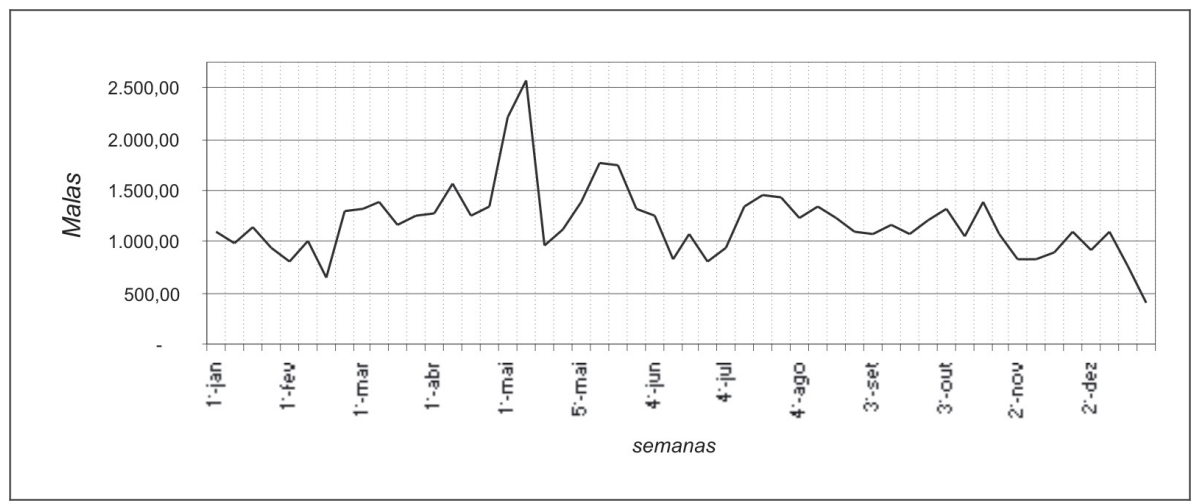

Fonte: Pesquisa de campo, 2002.

${ }^{12}$ A diversidade de relações dos ITs foi uma das constatações da amostra. Ao mesmo tempo em que uma empresa, representada por IT2, tem uma receita média líquida mensal de $\mathrm{R} \$ 737,00$, outra empresa, representada por IT1, tem nesta mesma receita um valor de $\mathrm{R} \$ 183.300,00$. 
A partir do gráfico acima é possível constatar que as vendas do produto se elevam a partir do final de fevereiro até o final de agosto. Dentro deste período dá-se destaque ao mês de março, com o fim das férias da maior parte da população gaúcha, ao mês de junho, marcado por datas como o Dia dos Namorados, e principalmente ao mês de maio, onde a primeira e a segunda semana são os maiores picos de vendas do produto, decorrência do Dia das Mães.

\subsection{Caracterização dos agentes envolvidos com o atacado e o varejo}

Nas Centrais de Abastecimento, tanto o volume comercializado quanto a evolução dos preços ocorreu de forma diferenciada. Esta diferença está demonstrada na Tabela 2 .

Tabela 2 - Preços de venda da samambaia-preta, em 1998 e 2002, e volume médio mensal vendido em 2002 nas Centrais de Abastecimento acompanhadas:

\begin{tabular}{|c|c|c|c|c|}
\hline & $\begin{array}{c}\text { Preço de venda } \\
\text { (R\$/mala) } \\
\text { em jan. de 1998 }\end{array}$ & $\begin{array}{c}\text { Preço de venda } \\
\text { (R\$/mala) } \\
\text { em dez. de 2002 }\end{array}$ & $\begin{array}{c}\text { Variação } \\
\text { acumulada de } \\
\text { preços (\%) }\end{array}$ & $\begin{array}{c}\text { Volume médio } \\
\text { mensal } \\
\text { comercializado } \\
\text { em 2002 (malas) }\end{array}$ \\
\hline Porto Alegre & 2,00 & 2,00 & - & 12.225 \\
\hline Curitiba & $5,84^{*}$ & 3,98 & $-32,85$ & 5.711 \\
\hline Campinas & 2,50 & 3,00 & 20,00 & 18.266 .785 \\
\hline CEAGESP & 2,37 & 3,33 & 40,51 & 5.222 \\
\hline
\end{tabular}

Fonte: CEASA/RS - Setor de Análise e Informações, DITEC/CEASA/PR, CEASA/Campinas - Mercado de Flores, CEAGESP - Seção de Economia e Desenvolvimento, 1998 e 2002.

* Dado de 2001, ano em que se iniciou o comércio de flores na CEASA/PR.

Enquanto em Porto Alegre, o preço manteve-se fixado a $\mathrm{R} \$ 2,00$ por “mala” de janeiro de 1998 a dezembro de 2002, neste mesmo período o preço nominal aumentou na CEAGESP e na CEASA/Campinas, porém com variação abaixo dos índices de inflação ${ }^{13}$ acumulada. No caso da CEASA/PR, a deflação nominal dos preços apontada tem como justificativa a liberalização do comércio da espécie por parte do Governo do

${ }^{13}$ IGP-DI/FGV acum. jan. 1998/ dez. 2002: 86,14\% . INPC/FIBGE acum. jan. 1998/ dez. 2002: 46,05\% (IEPE-UFRGS, 2003). 
estado do Paraná há pouco tempo ${ }^{14}$, causando um aumento na oferta do produto. Em nenhum dos locais onde houve variação, a volatilidade dos preços entre os meses se correlaciona significativamente com o volume em "malas", nem apresenta sazonalidade significativa.

No caso da CEAGESP e CEASA/Campinas, apesar de apresentarem um crescimento absoluto, os preços nestas duas centrais não apontam uma tendência determinística de crescimento aceitável. Apontando em ambos os casos uma tendência aleatória ou estocástica. As funções autoregressivas ${ }^{15}$ colocam, para a CEAGESP um preço de equilíbrio estável de $\mathrm{R} \$ 3,33$, e para CEASA/Campinas um preço de equilíbrio estável de R $\$ 3,00$.

Além da diferença na variação dos preços, a Tabela 2 demonstra ainda a diferença existente entre os volumes comercializados nos mercados. Enfatiza-se a concentração do produto ocorrente na CEASA/Campinas, possivelmente um dos maiores centros de comercialização do produto no país, juntamente com Holambra ${ }^{16}$, suprido por folhagens de diversas regiões.

Neste mesmo período, os volumes comercializados não demonstraram tendência de crescimento na central de Porto Alegre. Já na CEASA/ Campinas o volume cresce tendencialmente a uma taxa de 1,65\% ao mês; e na CEAGESP a taxa de variação é de $-1,67 \%$, ou seja, um crescimento negativo do volume comercializado.

A diferença entre as centrais também é evidenciada sazonalmente. O Gráfico 2 demonstra os índices sazonais, calculados entre 1998 e 2002, da central de Porto Alegre, de Campinas e da CEAGESP.

\footnotetext{
${ }^{14}$ No Estado do Paraná, até o final de 2001, o comércio e a extração da samambaia-preta era proibido pela legislação ambiental lá vigente, como é hoje no Rio Grande do Sul. ${ }^{15}$ Campinas: $p_{\mathrm{t}}=0,51+0,83 p_{\mathrm{t}-1}+u_{\mathrm{t}}$ sendo $r^{2}=0,7419 ; t_{c}=12,8018$ e $d=2,3914$. CEAGESP: $p_{\mathrm{t}}=0,50+0,85 p_{\mathrm{t}-1}+u_{\mathrm{t}}$ sendo $r^{2}=0,8142 ; t_{c}=15,8052$ e $d=1,7828$.

${ }^{16}$ Referente ao município de Holambra-SP, não foi possível levantar informações sobre a Cooperativa Veiling-Holambra, seu principal centro. Obtiveram-se informações somente do IT1, que demonstrou uma grande concentração do produto em relação aos outros agentes.
} 
Extração e Comercialização de Folhagens Ornamentais da Mata Atlântica:

o Caso da Verdes (Rumohra adiantiformis) no RS*

Gráfico 2 - Índice sazonal do volume de vendas ao longo do ano:

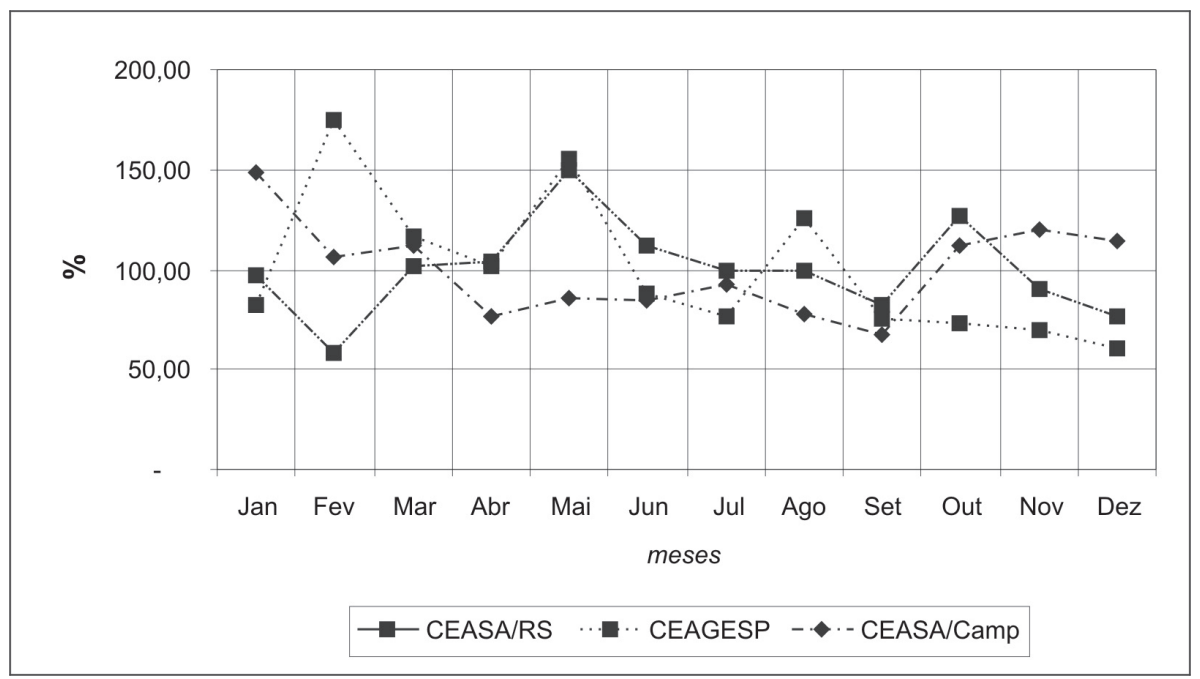

Fonte: CEASA/RS - Setor de Análise e Informações, CEAGESP - Seção de Economia e Desenvolvimento, CEASA/Campinas - Mercado de Flores; 1998, 1999, 2000, 2001 e 2002.

Apesar da CEAGESP e da CEASA/RS apresentarem elevada comercialização no mês de maio, assim como constatado entre os IPs, a central paulista apresentou seu maior pico de vendas em fevereiro, mês que no Rio Grande do Sul é caracterizado como de baixa atividade. Comparando à CEASA/Campinas, a sazonalidade é totalmente inversa, já que os meses de maiores vendas são justamente os de primavera e verão.

Considerando que maior parte da folhagem extraída na Encosta Atlântica do Rio Grande do Sul vai para a região Sudeste, é possível constatar que, neste caso, a redução no comércio, evidenciada localmente nos meses de verão, é causada pelos próprios agentes locais.

No mercado varejista, pode-se constatar que as floriculturas que estabeleceram relações de compra diretamente com a região de corte, beneficiaram-se com um desconto de $\mathrm{R} \$ 0,50$ a $\mathrm{R} \$ 1,00$ por “mala” na compra da folhagem, enquanto as que adquirem o produto junto à CEASA/RS adquirem a samambaia por R 2,00 a "mala".

Nos estabelecimentos varejistas, a folhagem geralmente é usada para buquês de flores, arranjos ornamentais e, com maior quantidade, em coroas fúnebres. As perdas de mercadoria ocorrida no processo de 
confecção destes arranjos foram estimadas, a partir do relato de alguns proprietários de floriculturas, em torno de $5 \%$ a $10 \%$ (Pesquisa de campo, 2002). Em conseqüência desta situação, muitos proprietários de floriculturas apontaram para uma crescente substituição da espécie Rumohra adiantiformis por folhas de cipreste e palmeira, mais baratas e resistentes. Este processo de substituição pode estar acarretando uma queda na demanda do produto, fato causador da depreciação real dos preços ao longo do tempo.

Há muito tempo, as relações de preços no início da cadeia não têm sofrido alteração ${ }^{17}$, pelo contrário os preços praticados têm sofrido pequenas deflações com o excessivo aumento da oferta, decorrente do elevado número de "atravessadores" e extrativistas. Essa deflação, confrontada com o aumento nos custos de transporte e nos custos de vida, reduz sensivelmente a renda das famílias de extratores de samambaia locais.

Em uma comparação na estrutura de mercado do início ao final da cadeia, nota-se, de acordo com o número de firmas, formas de concorrência e formação dos preços, uma evidente concentração do mercado do extrativismo ao mercado atacadista. No início do processo de transferência (SAs e IPs), identifica-se uma série de fatores característicos de uma concorrência quase que perfeita, ou seja, elevado número de atores, com características semelhantes, em concorrência, com liberdade de entrada e saída da atividade, demanda elástica (tomadores de preços) e tendência ao lucro normal ${ }^{18}$, além, claro, do produto homogêneo. Entre os ISs evidencia-se uma concentração local ${ }^{19}$, onde poucos têm acesso aos contatos externos ao RS, além de considerável diferenciação entre estes. Esta concentração e assimetria acirram-se nos ITs e nas Centrais Atacadistas, constituindo um oligopólio ${ }^{20}$ com altas margens de receita e lucro e grande poder de barganha na formação de preços.

\footnotetext{
${ }^{17}$ Segundo depoimentos de extrativistas e “atravessadores”, o preço nominal pago pelo produto não se eleva desde o início do Plano Real.

${ }^{18}$ Lucro suficiente para reproduzir o capital existente na firma. No caso de famílias de extrativistas, suficiente para sobrevivência destas.

${ }^{19}$ Estima-se que o IS1 negocie mais da metade da carga que sai do Litoral Norte do RS em direção a outros estados.

${ }^{20}$ Oligopólio heterogêneo se considerar a mesma espécie, proveniente de diferentes regiões, com diferentes aspectos qualitativos, e diferentes estruturas de custo no transporte.
} 
Frente a essa estrutura "oligopsônica", uma das medidas para aumentar o poder de barganha dos agentes primários (SAs e IPs), seria a organização de sindicatos, associações e/ou cooperativas. Porém, no que tange à organização formal, foi identificada a inexistência de acordos horizontais entre os agentes ${ }^{21}$. Sem equívoco, pode-se afirmar que as dificuldades de organização também contribuem para a redução dos preços recebidos por estes agentes.

\section{Considerações finais}

De uma maneira geral, os resultados obtidos permitiram constatar uma profunda desestruturação na base da cadeia da verdes extraída na região da Encosta Atlântica do RS, tanto em termos de organização dos agentes quanto em termos de informação sobre a atividade. Esta situação parece estar relacionada com a clandestinidade da atividade extrativista e à informalidade das relações comerciais.

Foi possível constatar a existência de uma remuneração bastante diferenciada entre os diferentes agentes envolvidos nesta cadeia. Com efeito, os intermediários terciários e os atacadistas, identificados como os formadores de preços da cadeia, obtêm uma remuneração significativamente superior à margem obtida pelos demais. Ao mesmo tempo em que o poder aquisitivo das famílias residentes na Encosta Atlântica do RS diminui, devido ao aumento do custo de vida relacionado à situação de tomadores de preços.

Fica evidente que a folhagem tem uma demanda quase que infinitamente elástica, gerando um baixo poder de mercado aos agricultores. Porém, a necessidade da implementação de mecanismos que redistribuam de maneira mais equilibrada os ganhos entre os diferentes elos da cadeia é também evidente. Esta conquista passa necessariamente pela regulamentação da atividade pelo poder público do estado do RS e pela

\footnotetext{
${ }^{21} \mathrm{Na}$ disputa entre intermediários locais e de outros estados que, há aproximadamente oito anos atrás, foi tentada uma greve dos primeiros para melhorar o preço pago pelas empresas "de fora". Como resultado, alguns IPs de menor importância conseguiram contatar diretamente tais empresas, "furando" a greve e vendendo a samambaia por preços ainda menores dos que já estavam sendo praticados. Essa prática tem se repetido durante os últimos anos (RIBAS et al., 2002).
} 
organização dos agentes envolvidos (sobretudo os extrativistas e os intermediários primários). Ou seja, o licenciamento desta atividade pode efetivamente acarretar um novo equilíbrio na estrutura do mercado, seja pela modificação das relações entre os agentes, seja pelo aumento do poder de barganha dos extratores de samambaia.

Os pontos fundamentais para a melhoria dos preços pagos são a melhoria da qualidade e padronização do produto final e a busca por novos mercados com carência de oferta, em locais mais próximos ao Litoral Norte do RS, reduzindo os custos de intermediação. Identificouse então a necessidade da implementação de padrões de qualidade com vistas à classificação do produto, sobretudo em nível da atividade de extração, além de uma melhoria no condicionamento da folhagem e nas condições de transporte, principalmente a nível local.

Em termos de políticas públicas, no entanto, as ações que visam esse mercado não são tão importantes quanto outras políticas que busquem alternativas de desenvolvimento para as famílias locais. Alternativas que sejam mais sustentáveis ambientalmente, como o incentivo à implantação de sistemas agroflorestais que se desviam do conflito preservação ambiental e reprodução social, poderiam ser também mais sustentáveis economicamente, já que o mercado de verdes não aponta para um futuro promissor para a atividade.

A crescente substituição de verdes por outras espécies de folhagens na confecção de arranjos, pode estar acarretando uma queda na demanda do produto ao longo do tempo nos grandes centros de comercialização, fato causador da depreciação real dos preços ao longo da cadeia. Esta depreciação, ligada a uma concorrência via-preço das estruturas oligopolizadas da cadeia (intermediários terciários e atacadistas) e ao poder de barganha que estes possuem sobre os demais agentes, tem por conseqüência a rigidez dos valores nominais pagos aos agentes primários (extrativistas e intermediários primários), tomadores de preços.

No que tange aos aspectos conceituais e metodológicos, para este estudo seria mais plausível trabalhar com um modelo que permita análises e previsões do comportamento das margens de comercialização e das parcelas do dispêndio do consumidor que cabe a cada grupo social. No entanto, devido à dificuldade de levantamento e precariedade das informações obtidas, a escolha do método de filière simplificada foi o de 
- Extração e Comercialização de Folhagens Ornamentais da Mata Atlântica: o Caso da Verdes (Rumohra adiantiformis) no RS*

maior adequação e pertinência para o estudo do fluxo comercial e produtivo desta pteridófita. Cabe deixar claro ainda que, apesar do conceito de filière simplificada ter permitido apreender com objetividade e transparência as transações comerciais incidentes ao longo do processo de transferência do produto, outros aspectos foram incorporados ao método de análise para a realização de uma leitura mais ampla dos mercados.

Por fim, com os resultados produzidos ao longo desta pesquisa, pode-se afirmar que a extração e o comércio deste recurso florestal configura uma atividade passível de incrementar a renda dos agricultores familiares, desde que seja de uma forma complementar à atividade agrícola e sabendo aproveitar os períodos de maior e menor demanda do produto, relacionado a um manejo correto e sustentável da folhagem. Ao explicitar a importância econômica e social da atividade extrativista para esta população, aponta-se para a necessidade de profundas alterações na Legislação Ambiental vigente no Rio Grande do Sul. Além de permitir uma reestruturação na cadeia de comercialização, a readequação da Legislação Ambiental pode regularizar a implementação de políticas públicas voltadas à redução da pobreza rural na região da Encosta Atlântica do Rio Grande do Sul, além de incitar os agricultores extrativistas a implementarem processos de produção que acarretem um menor impacto ambiental.

\section{Referências bibliográficas}

ANAMA, PGDR-UFRGS, RS-RURAL. Avaliação etnobiológica e socioeconômica da samambaia-preta (Rumohra adiantiformis (G.Forest.) Ching) na região da Encosta Atlântica do Estado. Porto Alegre, junho de 2003, 111p. (Relatório de Pesquisa, Pesquisa por Demanda - RS RURAL, Secret. Agricultura e Abastecimento, RS).

BATALHA, Mário Otávio. Sistemas Agroindustriais: Definições e Correntes Metodológicas. In: BATALHA, Mário Otávio (coord.). Gestão Agroindustrial, vol. 1. São Paulo: Atlas, 1997. p. 23-48.

COELHO DE SOUZA, G. et. al. Avaliação etnobiológica e socioeconômica da samambaia preta (Rumohra adiantiformis (G. FOREST.) CHING) na região da Encosta Atlântica do Estado. Projeto de Pesquisa - Pro- 
grama de Pós-graduação em Desenvolvimento Rural da (PGDR) UFRGS e Ação Nascente Maquiné (ANAMA), setembro de 2000. 15 p. (Pesquisa por Demanda - RS RURAL, Secret. Agricultura e Abastecimento, RS).

CONSÓRCIO MATA ATLÂNTICA \& UNICAMP. Reserva da Biosfera da Mata Atlântica. Plano de ação v.1: Referências básicas, São Paulo, 1992.

FEPAM. Diretrizes ambientais para o desenvolvimento do Litoral Norte. In: FEPAM (org.). Cadernos de planejamento e gestão do litoral ambiental, Porto Alegre, vol. 1, 2000. 96p.

FONSECA, J. S.; MARTINS, G. A.; TOLEDO, G. L. Estatística Aplicada. São Paulo: Atlas, 1984. p. 11-156.

GERHARDT, C. H. et. al. Diagnóstico socioeconômico e ambiental do município de Maquiné - RS: perspectivas para um desenvolvimento rural sustentável. Relatório de Pesquisa, ANAMA - PGDR/ UFRGS - Prefeitura Municipal de Maquiné, Porto Alegre, 2000. 56p.

GERHARDT, C. H. \& MIGUEL, L.A. Evolução dos sistemas agrários do litoral norte do estado do Rio Grande do Sul: o caso do município de Maquiné - RS. In: Encontro da Sociedade Brasileira de Sistemas de Produção, 4, 2001, Belém. Belém: SBSP/ UFPA-CA-NEAF/ EMBRAPACPATC, 2001. 19p.

GRAZIANO DA SILVA, José. A Nova Dinâmica da Agricultura Brasileira. Campinas: UNICAMP, 1996. p. 61-72.

GREENE, W. H. Econometric Analisys. 3 ed. Upper Saddle River: Prentice Hall, 1997.

GUJARATI, Damodar N. Econometria Básica. São Paulo: Makron Books, 2000. 846p.

IEPE-UFRGS. Boletim Econômico IEPE. Porto Alegre: UFRGS, mar. 2003. p.5.

KUPFER, D. \& HASENCLEVER, L. (org.). Economia Industrial. Rio de Janeiro: Campus, 2002. 680p.

MATOS, Orlando C. Econometria Básica. São Paulo: Atlas, 2000. 300p. 
MILTON, S.J. \& MOLL, E.J. Effects of harvesting on frond production of Rumohra adiantiformis (Pteridophyta: Aspidiaceae) in south Africa. Journal of Applied Ecology, New York, n. 25, p. 725-743, 1988.

RIBAS, R. P. et. al. Aspectos econômicos e sociais da cadeia produtiva da Samambaia-preta (Rumohra adiantiformis (G. Forest.) Ching) na região da Encosta Atlântica do Estado do RS. In: Revista Redes, Santa Cruz do Sul, v. 7, n. 2, p. 153-166, 2002.

SARTOR, Juliane. Cadeia de flores e plantas ornamentais de jardim em Pareci Novo - Rio Grande do Sul. Porto Alegre: PGDR/UFRGS, 2001. 117 p. (Dissertação, Mestrado em Desenvolvimento Rural).

VARIAN, H. R. Microeconomic analysis. 3 ed. New York: Norton \&Company, 1992.

ZERO HORA. Mata Atlântica é saqueada. Porto Alegre, 21 maio 2000. p. 50-51.

ZYLBERSZTAJN, Décio. Conceitos Gerais, Evolução e Apresentação do Sistema Agroindustrial. In: FAVANEVES, Marcos (org.). Economia e Gestão dos Negócios Agroalimentares. São Paulo: Pioneira, 2000. p. 1-21. 